\title{
Emergency department hyperoxia is associated with increased mortality in mechanically ventilated patients: a cohort study
}

David Page ${ }^{3}$, Enyo Ablordeppey ${ }^{1,2}$, Brian T. Wessman ${ }^{1,2}$, Nicholas M. Mohr ${ }^{4,5}$, Stephen Trzeciak ${ }^{6,7}$, Marin H. Kollef ${ }^{3}$, Brian W. Roberts ${ }^{7}$ and Brian M. Fuller ${ }^{1,2^{*}}$

\begin{abstract}
Background: Providing supplemental oxygen is fundamental in the management of mechanically ventilated patients. Increasing amounts of data show worse clinical outcomes associated with hyperoxia. However, these previous data in the critically ill have not focused on outcomes associated with brief hyperoxia exposure immediately after endotracheal intubation. Therefore, the objectives of this study were to evaluate the impact of isolated early hyperoxia exposure in the emergency department (ED) on clinical outcomes among mechanically ventilated patients with subsequent normoxia in the intensive care unit (ICU).

Methods: This was an observational cohort study conducted in the ED and ICUs of an academic center in the USA. Mechanically ventilated normoxic (partial pressure of arterial oxygen $\left(\mathrm{P}_{\mathrm{a}} \mathrm{O}_{2}\right)$ 60-120 mm Hg) ICU patients with mechanical ventilation initiated in the ED were studied. The cohort was categorized into three oxygen exposure groups based on $\mathrm{P}_{\mathrm{a}} \mathrm{O}_{2}$ values obtained after ED intubation: hypoxia, normoxia, and hyperoxia (defined as $\mathrm{P}_{\mathrm{a}} \mathrm{O}_{2}<60 \mathrm{mmHg}, \mathrm{P}_{\mathrm{a}} \mathrm{O}_{2}$ 60-120 mm Hg, and $\mathrm{P}_{\mathrm{a}} \mathrm{O}_{2}>120 \mathrm{~mm} \mathrm{Hg}$, respectively, based on previous literature).

Results: A total of 688 patients were included. ED normoxia occurred in 350 (50.9\%) patients, and 300 (43.6\%) had exposure to ED hyperoxia. The ED hyperoxia group had a median (IQR) ED $\mathrm{P}_{\mathrm{a}} \mathrm{O}_{2}$ of $189 \mathrm{~mm} \mathrm{Hg}$ (146-249), compared to an ED $P_{a} \mathrm{O}_{2}$ of $88 \mathrm{~mm} \mathrm{Hg}(76-101)$ in the normoxia group, $P<0.001$. Patients with ED hyperoxia had greater hospital mortality (29.7\%), when compared to those with normoxia (19.4\%) and hypoxia (13.2\%). After multivariable logistic regression analysis, ED hyperoxia was an independent predictor of hospital mortality (adjusted OR 1.95 (1.34-2.85)).

Conclusions: ED exposure to hyperoxia is common and associated with increased mortality in mechanically ventilated patients achieving normoxia after admission. This suggests that hyperoxia in the immediate post-intubation period could be particularly injurious, and targeting normoxia from initiation of mechanical ventilation may improve outcome.
\end{abstract}

Keywords: Hyperoxia, Mechanical ventilation, Emergency department

\footnotetext{
* Correspondence: fullerb@wustl.edu

'Department of Emergency Medicine, Washington University School of Medicine in St. Louis, St. Louis, MO 63110, USA

${ }^{2}$ Department of Anesthesiology, Division of Critical Care Medicine,

Washington University School of Medicine in St. Louis, St. Louis, MO 63110,

USA

Full list of author information is available at the end of the article
} 


\section{Background}

Providing supplemental oxygen is ubiquitous in the management of mechanically ventilated patients. Guidelines for the provision of oxygen give recommendations for target oxygen saturations and for the weaning of oxygen therapy [1]. Despite this, the titration of supplemental oxygen in mechanically ventilated patients is infrequent with resultant hyperoxia being common in the intensive care unit (ICU) [2].

While the deleterious effects of hypoxia are appreciated and actively avoided, hyperoxia is regularly accepted [2-4]. This pendulum swing toward hyperoxia may be associated with harm, as increasing amounts of data show worse clinical outcomes associated with elevated levels of arterial oxygen [5, 6]. Patients suffering from an acute ST-elevation myocardial infarction provided with supplemental oxygen were found to have an increase in recurrent myocardial infarction and arrhythmia and larger myocardial infarct size at 6 months [7]. In mechanically ventilated ICU patients, hyperoxia has been associated with mortality and a decrease in ventilatorfree days $[8,9]$. In patients resuscitated from cardiac arrest and post-ischemic stroke, hyperoxia has also been linked with worse outcome [10-13]. Finally, patients with traumatic brain injury have increased mortality and worse functional outcomes associated with hyperoxia [14-16]. However, these previous data in the critically ill have focused on outcomes associated with relatively prolonged hyperoxia, with the assessment of hyperoxia exposure during the first 24-72 hours of ICU stay, and up to the entire period of mechanical ventilation [5]. Animal data have shown that the negative consequences associated with hyperoxia can be both time-dependent and dose-dependent, and hyperoxia of only a few hours duration can provoke deleterious changes in inflammation and pulmonary mechanics; yet the effect of a relatively brief exposure to hyperoxia in critically ill patients prior to ICU admission is unknown [17-20].

The emergency department (ED) could be a location that provides both impactful and scalable data to study the effects of initial hyperoxia on outcome: lengths of stay for mechanically ventilated ED patients are long enough for hyperoxia to potentially initiate harm, yet short enough to provide novel data on comparatively brief exposures to hyperoxia. Also, excessive administration of oxygen in the ED is common [21-23]. The objectives of this study were to assess the association between the initial exposure to hyperoxia, immediately after endotracheal intubation in the ED, and clinical outcomes among patients who were subsequently normoxic while in the ICU. We hypothesized that hyperoxia in the ED would be associated with an increase in hospital mortality and increased lengths of stay.

\section{Methods}

\section{Study design and participants}

This was a cohort study, using a database of patients that had mechanical ventilation initiated in the ED at a tertiary academic medical center (September 2009 to March 2016). The database was created as part of a clinical investigation that assessed outcomes associated with the implementation of ED lung-protective mechanical ventilation $[24,25]$. All mechanically ventilated ED patients were screened for inclusion. The inclusion criteria were the following: (1) adult patients (age $\geq 18$ years); (2) mechanical ventilation via an endotracheal tube; and (3) normoxia (partial pressure of arterial oxygen $\left(\mathrm{P}_{\mathrm{a}} \mathrm{O}_{2}\right) 60-120 \mathrm{~mm}$ $\mathrm{Hg}$ ) on day 1 of ICU admission. The analysis was restricted to those patients with ICU normoxia, given the fact that (1) longer periods of exposure to hyperoxia in the ICU have been studied in the past; (2) this approach allowed us to better isolate a relatively brief hyperoxia exposure (i.e. in the ED) to test its association with outcome; and (3) the association between ED hyperoxia and outcome in mechanically ventilated patients had not been studied previously. Exclusion criteria were as follows: (1) death or discontinuation of mechanical ventilation within 24 hours of intubation; (2) chronic respiratory failure requiring mechanical ventilation; (3) presence of a tracheostomy; (4) transfer to another hospital; and (5) presence of acute respiratory distress syndrome (ARDS) while in the ED (defined by the Berlin criteria) [26]. This study was approved by the institutional review board under waiver of informed consent.

\section{Procedures}

Demographic data, comorbidities, laboratory values, vital signs, illness severity, ED length of stay, and etiology of respiratory failure were collected. Data on treatments provided in the ED included the use of vasopressors and antibiotics and amount of intravenous fluid.

Mechanical ventilator settings provided in the ED were collected, along with gas exchange variables, plateau pressure, static compliance of the respiratory system, and driving pressure. Ventilator settings from the ICU were collected twice daily, for up to 2 weeks.

The definitions of comorbid conditions are provided in Additional file 1. Driving pressure $\left(\mathrm{cm} \mathrm{H}_{2} \mathrm{O}\right)$ was calculated as plateau pressure minus positive endexpiratory pressure (PEEP). Static compliance $(\mathrm{mL} / \mathrm{cm}$ $\left.\mathrm{H}_{2} \mathrm{O}\right)$ of the respiratory system $\left(\mathrm{C}_{\mathrm{RS}}\right)$ was calculated as:

$$
\mathrm{C}_{\mathrm{RS}}=\text { Tidal volume } /(\text { Plateau pressure }-\mathrm{PEEP}) \text {. }
$$

The primary outcome was in-hospital mortality. Secondary outcomes were ventilator-free, ICU-free, and hospital-free days. Patients were followed until hospital discharge or death. 


\section{Statistical analysis}

Patient characteristics were assessed with descriptive statistics, including mean (standard deviation (SD)), median (interquartile range (IQR)), and frequency distributions. Linear interpolation was used to deal with missing data on lactate values ( $\mathrm{n}=157$ patients). The cohort was a priori categorized into three oxygen exposure groups based on $\mathrm{P}_{\mathrm{a}} \mathrm{O}_{2}$ values obtained after intubation (i.e. in the ED, one arterial blood gas per patient). Hypoxia was defined as $\mathrm{P}_{\mathrm{a}} \mathrm{O}_{2}<60 \mathrm{~mm} \mathrm{Hg}$, normoxia as $\mathrm{P}_{\mathrm{a}} \mathrm{O}_{2} 60-$ $120 \mathrm{~mm} \mathrm{Hg}$, and hyperoxia as $\mathrm{P}_{\mathrm{a}} \mathrm{O}_{2}>120 \mathrm{~mm} \mathrm{Hg}$. Recognizing that there is no formal definition of hyperoxia, a $\mathrm{P}_{\mathrm{a}} \mathrm{O}_{2}$ cutoff value of $120 \mathrm{~mm} \mathrm{Hg}$ was used as it is congruent with the cutoff value used in other cohort studies that examined ICU hyperoxia exposure in a diverse cohort of mechanically ventilated patients (i.e. analysis not isolated to patients post cardiac arrest or those with stroke or traumatic brain injury) [8, 9, 27]. In a post hoc analysis, the hyperoxia group was further categorized into mild $\left(\mathrm{P}_{\mathrm{a}} \mathrm{O}_{2}\right.$ 121-200 mm Hg), moderate $\left(\mathrm{P}_{\mathrm{a}} \mathrm{O}_{2} 201-\right.$ $300 \mathrm{~mm} \mathrm{Hg})$, and severe $\left(\mathrm{P}_{\mathrm{a}} \mathrm{O}_{2}>300 \mathrm{~mm} \mathrm{Hg}\right)$ hyperoxia subgroups.

To assess predictors for the primary outcome of hospital mortality, categorical characteristics were compared using the chi-square test. Continuous characteristics were compared using analysis of variance (ANOVA) or the Kruskal-Wallis test depending on the distribution of the data. The Bonferroni correction was used to correct for multiple comparisons, and differences in $\mathrm{P}_{\mathrm{a}} \mathrm{O}_{2}$ categories were considered statistically significant if $P$ was $<0.017$. Time (in days) to the primary outcome was assessed with the Kaplan-Meier survival estimate and log-rank test, comparing the normoxic and hyperoxic groups. A second Kaplan-Meier survival estimate was also calculated, which included the hyperoxic subgroups.

To determine independent predictors of mortality, a backward, stepwise, multivariable logistic regression model was used to evaluate death as a function of oxygen exposure group. Clinically relevant variables that were statistically significant in univariate analysis at $P<$ 0.05 were candidates for model inclusion. The primary exposure of interest was ED $\mathrm{P}_{\mathrm{a}} \mathrm{O}_{2}$. As fraction of inspired oxygen $\left(\mathrm{F}_{\mathrm{i}} \mathrm{O}_{2}\right)$ and PEEP are significantly linked to the exposure and statistically collinear with it, they were not entered into the multivariable model, neither was $\mathrm{P}_{\mathrm{a}} \mathrm{O}_{2}: \mathrm{F}_{\mathrm{i}} \mathrm{O}_{2}$ (expected differences based on the primary exposure group). Variables for inclusion or exclusion from the model were selected in sequential fashion based on the significance level of 0.10 for entry and 0.10 for removal. Normality, statistical interactions, and collinearity (i.e. variance inflation factor) were assessed, and the model used variables that were statistically independent. Model goodness of fit was assessed with the Hosmer-Lemeshow test and by examining residuals.
Adjusted odds ratios (OR) and corresponding 95\% confidence intervals $(\mathrm{CI})$ are reported for the multivariable model, adjusted for all variables in the model. All tests were two-tailed, and a $P$ value $<0.05$ was considered statistically significant.

\section{Results}

\section{Study population}

The flow diagram of inclusions, exclusions, and the final study population are presented in Fig. 1. A total of 688 patients that were normoxic in the ICU were included in the final analysis.

Table 1 presents baseline characteristics of the study population related to the ED oxygenation group. The median (IQR) ED length of stay (hours) was 5.4 (3.57.9), with no difference in ED length of stay between the groups. There were no significant differences between the groups in comorbid conditions or indications for mechanical ventilation. Illness severity, as measured by Acute Physiology and Chronic Health Evaluation II (APACHE II) score, was higher in the ED hypoxia group. The most common reason for initiation of mechanical ventilation was sepsis.

\section{Oxygenation and mechanical ventilation characteristics}

Table 2 shows the ventilator variables in the ED and ICU. There were 300 patients (43.6\%) who had exposure to ED hyperoxia, 350 (50.9\%) who had exposure to ED normoxia, and 38 (5.5\%) who had exposure to ED hypoxia.

Median (IQR) $\mathrm{F}_{\mathrm{i}} \mathrm{O}_{2}$ was 80\% (50-100) in patients in the ED hyperoxia group, which was significantly higher than the $\mathrm{F}_{\mathrm{i}} \mathrm{O}_{2}$ in patients in the ED normoxia (68\% (40$100)$ ) and hypoxia $(60 \%(40-80))$ groups, $P=0.004$. In the ED hyperoxia group, there was also a significantly higher median $\mathrm{P}_{\mathrm{a}} \mathrm{O}_{2}(189 \mathrm{~mm} \mathrm{Hg}(146-249))$, and $\mathrm{P}_{\mathrm{a}} \mathrm{O}_{2}$ :$\mathrm{F}_{\mathrm{i}} \mathrm{O}_{2}(270(198-360)), P<0.001$.

There were no significant clinical differences between the groups with respect to day 1 ICU oxygenation and mechanical ventilation variables, though some statistical differences existed. Oxygenation and mechanical ventilation variables remained fairly static over the ICU stay, with little difference between day 1 variables and those calculated over the entire duration of mechanical ventilation (Additional file 2: Table S1).

\section{Clinical outcomes}

In the entire cohort, hospital mortality occurred in 162 (23.5\%) patients. Patients with ED hyperoxia had greater hospital mortality (29.7\%), when compared to those with normoxia (19.4\%) and hypoxia (13.2\%). On Kaplan-Meier analysis, survival diverged significantly between the hyperoxia and normoxia groups (log-rank $P=0.021$, Fig. 2). 


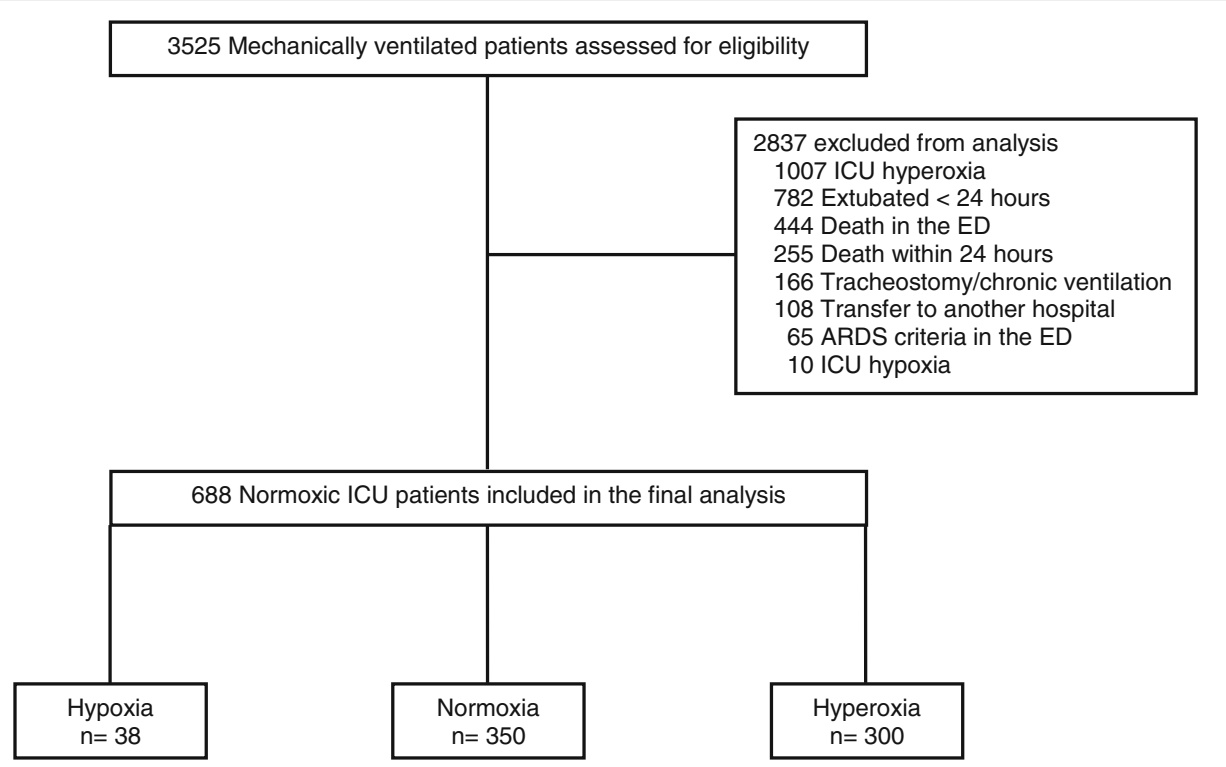

Fig. 1 Study flow diagram

The primary outcome analysis is shown in Table 3. The multivariable model was adjusted for age, gender, APACHE II, lactate, ED tidal volume, ED plateau pressure, ICU $\mathrm{P}_{\mathrm{a}} \mathrm{O}_{2}$, and oxygen exposure group. After multivariable logistic regression analysis, ED hyperoxia was an independent predictor of hospital mortality (aOR 1.95 (1.34-2.85)). The complete multivariable model results are shown in Additional file 3: Table S2.

Secondary outcomes are also presented in Table 3. Compared to the normoxia group, there was a decrease in ventilator-free days (mean difference 3.7; 95\% CI 2.0 to 5.4), ICU-free days (mean difference 3.5 ; $95 \%$ CI 1.9 to 5.1), and hospital-free days (mean difference 2.9; 95\% CI 1.5 to 4.3 ) associated with ED hyperoxia, $P<0.001$ for all.

The post hoc analysis examined mortality across hyperoxia subgroups. As the level of hyperoxia increased, hospital mortality was greater, (mild hyperoxia $28.0 \%$, moderate hyperoxia $30.2 \%$, severe hyperoxia $34.8 \%$ ), though this was not statistically significantly different between the hyperoxia subgroups (Fig. 3). On Kaplan-Meier analysis, survival diverged significantly between the normoxia group and the hyperoxia subgroups (log-rank $P<0.001$, Additional file 4: Figure S1).

\section{Discussion}

\section{Key findings}

This observational cohort study was conducted to examine the association between early hyperoxia exposure and clinical outcomes in mechanically ventilated patients with normoxia during their ICU stay. We found that the liberal use of oxygen in the ED was common, with a median (IQR) $\mathrm{F}_{\mathrm{i}} \mathrm{O}_{2}$ of $70 \%(47-100)$, and a commensurate pre-ICU hyperoxia rate of $43.6 \%$.
Pre-ICU exposure to hyperoxia in the ED was associated with a mortality rate of $29.7 \%$, higher than in patients in both the hypoxia (13.2\%) and normoxia (19.4\%) groups. After controlling for confounders, including components of lung-protective ventilation (i.e. tidal volume, plateau pressure) and for baseline imbalances, hyperoxia remained an independent predictor of hospital mortality in multivariable analysis. Additionally, hospital mortality worsened across the hyperoxia subgroups. These data are congruent with prior studies of more prolonged exposure to hyperoxia in the ICU, yet to our knowledge this is the first study demonstrating an association between a comparatively brief early exposure to hyperoxia prior to ICU arrival, and worse clinical outcomes among mechanically ventilated patients [28].

\section{Relationship to prior work}

Clinical guidelines recommend targeting oxygen saturations at $94-98 \%$ for most acutely ill patients, and recommend reducing oxygen therapy in patients with satisfactory oxygen saturation [1]. In an observational study of 101 mechanically ventilated patients in the ICU, patients spent $>70 \%$ of their total mechanical ventilation time with peripheral arterial oxygen saturation $\left(\mathrm{S}_{\mathrm{p}} \mathrm{O}_{2}\right)$ values of $96-100 \%$, with mean $\mathrm{P}_{\mathrm{a}} \mathrm{O}_{2}$ values of $144 \mathrm{~mm} \mathrm{Hg}$ [29]. In 51 patients mechanically ventilated for $>48$ hours, the majority of time was spent with $\mathrm{S}_{\mathrm{p}} \mathrm{O}_{2}>98 \%$ and $50 \%$ of all observations revealed hyperoxia [4]. A Dutch study of 126,778 arterial blood gas measurements from over 5000 mechanically ventilated ICU patients revealed a $\mathrm{P}_{\mathrm{a}} \mathrm{O}_{2}>120 \mathrm{~mm} \mathrm{Hg}$ in $25 \%$ of the measurements, yet only $25 \%$ of the time was $\mathrm{F}_{\mathrm{i}} \mathrm{O}_{2}$ decreased [2]. Finally, data from a single-center and multi-center study has shown that 
Table 1 Baseline characteristics at the time of intubation

\begin{tabular}{|c|c|c|c|c|c|}
\hline & $\begin{array}{l}\text { All subjects } \\
n=688\end{array}$ & $\begin{array}{l}\text { ED hypoxia } \\
n=38\end{array}$ & $\begin{array}{l}\text { ED normoxia } \\
\mathrm{n}=350\end{array}$ & $\begin{array}{l}\text { ED hyperoxia } \\
n=300\end{array}$ & $P$ value \\
\hline Age (years) & $59.1(16.0)$ & $55.0(16.7)$ & $60.1(14.7)$ & $58.7(17.1)$ & 0.024 \\
\hline Female gender, $n(\%)$ & $290(42.2)$ & $15(39.5)$ & $166(47.4)$ & $106(35.3)$ & 0.015 \\
\hline \multicolumn{6}{|l|}{ Race, $n(\%)$} \\
\hline Black & $369(53.6)$ & $23(60.5)$ & $183(52.3)$ & $162(54.0)$ & \multirow[t]{3}{*}{0.661} \\
\hline White & $317(46.1)$ & $15(39.5)$ & $164(46.9)$ & $134(44.7)$ & \\
\hline Other & $7(1.0)$ & $0(0)$ & $3(0.9)$ & $4(1.3)$ & \\
\hline \multicolumn{6}{|l|}{ Comorbidities, n (\%) } \\
\hline Chronic obstructive pulmonary disease & $234(34.0)$ & $14(36.8)$ & $122(34.9)$ & $98(32.7)$ & 0.383 \\
\hline Malignancy & $117(17.0)$ & $8(21.1)$ & $57(16.3)$ & $52(17.3)$ & 0.655 \\
\hline Congestive heart failure & $189(27.5)$ & $10(26.3)$ & $92(26.3)$ & $86(28.7)$ & 0.893 \\
\hline Diabetes mellitus & $252(36.6)$ & $19(50.0)$ & $125(35.7)$ & $107(35.7)$ & 0.289 \\
\hline End-stage renal disease & $52(7.6)$ & $5(13.2)$ & $24(6.9)$ & $23(7.7)$ & 0.498 \\
\hline Immunosuppression & $61(8.9)$ & $6(15.8)$ & $33(9.4)$ & $22(7.3)$ & 0.287 \\
\hline Cirrhosis & $48(7.0)$ & $1(2.6)$ & $26(7.4)$ & $21(7.0)$ & 0.660 \\
\hline \multicolumn{6}{|l|}{ Indication for mechanical ventilation, $n$ (\%) } \\
\hline Asthma & $18(2.6)$ & 0 & $8(2.3)$ & $10(3.3)$ & \multirow[t]{8}{*}{0.492} \\
\hline Chronic obstructive pulmonary disease & $77(11.2)$ & $4(10.5)$ & $39(11.1)$ & $34(11.3)$ & \\
\hline CHF/pulmonary edema & $42(6.1)$ & $5(13.2)$ & $24(6.9)$ & $13(4.3)$ & \\
\hline Sepsis & $237(34.4)$ & $17(44.7)$ & $117(33.4)$ & $102(34.0)$ & \\
\hline Trauma & $119(17.3)$ & $6(15.8)$ & $58(16.6)$ & $53(17.7)$ & \\
\hline Cardiac arrest & $42(6.1)$ & $1(2.6)$ & $17(4.9)$ & $24(8.0)$ & \\
\hline Drug overdose & $29(4.2)$ & $1(2.6)$ & $13(3.7)$ & $15(5.0)$ & \\
\hline Other & $129(18.9)$ & $4(10.5)$ & $74(21.1)$ & $49(16.3)$ & \\
\hline APACHE $\|$ score $^{d}$ & $16(12-20)$ & $19(14-25)$ & $16(12-20)$ & $15(11-20)$ & 0.011 \\
\hline Systolic blood pressure (mm Hg) & $117(94-145)$ & $105(75-148)$ & $117(97-145)$ & $118(95-144)$ & 0.708 \\
\hline Vasopressor infusion, $n$ (\%) & $178(25.9)$ & $15(39.5)$ & $85(24.3)$ & $77(25.7)$ & 0.238 \\
\hline Antibiotic administration, $n$ (\%) & $332(48.3)$ & $23(60.5)$ & $177(50.6)$ & $131(43.7)$ & 0.068 \\
\hline Lactate (mmol/L) & $2.3(1.5-4.2)$ & $3.0(2.0-5.9)$ & $2.2(1.4-3.9)$ & $2.3(1.5-4.2)$ & 0.047 \\
\hline Hemoglobin (g/dL) & $12.1(2.6)$ & $12.1(2.5)$ & $12.1(2.6)$ & $12.0(2.7)$ & 0.335 \\
\hline Intravenous fluids in ED (L) & $1.8(1.8)$ & $1.7(1.5)$ & $1.7(1.8)$ & $1.8(1.8)$ & 0.969 \\
\hline ED LOS (hours) & $5.4(3.5-7.9)$ & $5.9(3.8-8.4)$ & $5.6(3.7-8.1)$ & $5.3(3.5-7.5)$ & 0.985 \\
\hline
\end{tabular}

Continuous variables are reported as mean (standard deviation) and median (interquartile range). $P$ values are from the chi-square test for categorical variables, one-way analysis of variance for continuous variables, and the Kruskal-Wallis test (lactate, Acute Physiology and Chronic Health Evaluation (APACHE)). Bonferroni correction: $\alpha / n$ of comparisons $=0.05 / 3=0.017$. $C H F$ congestive heart failure, $L O S$ length of stay, $E D$ emergency department

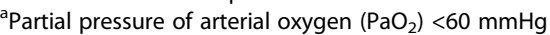

${ }^{\mathrm{b}} \mathrm{PaO}_{2}$ 60-120 mmHg

${ }^{\mathrm{c}} \mathrm{PaO}_{2}>120 \mathrm{mmHg}$

${ }^{\mathrm{d}}$ Modified score, which excludes the Glasgow Coma Scale

delivery of $\mathrm{F}_{\mathrm{i}} \mathrm{O}_{2}>90 \%$ is common and little titration of oxygen therapy occurs while patients are mechanically ventilated in the ED [21, 22]. Our current results, along with prior work in this area, further demonstrate that the liberal administration of oxygen is commonplace and hyperoxia is frequently tolerated, and extends these findings into the immediate post-intubation period in the ED.

With respect to clinical outcomes, there has been an increasing amount of data published in this domain over the last decade [6]. These data consist primarily of observational cohort studies with high heterogeneity among them in regards to methods, definition of hyperoxia, and the timing of the assessment of hyperoxia exposure $[5,6]$. However, general themes show an association between hyperoxia and harm in the majority of studies. Hyperoxia seems to have a time-dependent and dose-dependent association with outcome, whereby early and severe hyperoxia in the ICU are particularly 
Table 2 Ventilator variables in the emergency department and day 1 in the intensive care unit

\begin{tabular}{|c|c|c|c|c|c|}
\hline & $\begin{array}{l}\text { All subjects } \\
n=688\end{array}$ & $\begin{array}{l}\text { ED hypoxia }^{a} \\
n=38\end{array}$ & $\begin{array}{l}\text { ED normoxia } \\
n=350\end{array}$ & $\begin{array}{l}\text { ED hyperoxia } \\
n=300\end{array}$ & $P$ value \\
\hline \multicolumn{6}{|l|}{ Emergency department } \\
\hline Tidal volume (mL/kg PBW) & $7.5(6.4-8.6)$ & $6.6(6.1-7.7)$ & $7.5(6.4-8.6)$ & $7.6(6.7-8.7)$ & 0.001 \\
\hline Respiratory rate & $16(14-20)$ & $20(16-25)$ & $16(14-20)$ & $16(14-20)$ & $<0.001$ \\
\hline $\mathrm{FiO}_{2}$ & $70(47-100)$ & $60(40-80)$ & $68(40-100)$ & $80(50-100)$ & 0.004 \\
\hline PEEP & $5(5-7)$ & $8(5-10)$ & $5(5-7)$ & $5(5-5)$ & $<0.001$ \\
\hline $\mathrm{pH}$ & $7.29(7.21-7.38)$ & $7.26(7.16-7.33)$ & $7.29(7.21-7.38)$ & $7.29(7.21-7.39)$ & 0.354 \\
\hline $\mathrm{PaO}_{2}(\mathrm{~mm} \mathrm{Hg})$ & $110(82-179)$ & $54(51-55)$ & $88(76-101)$ & $189(146-249)$ & $<0.001$ \\
\hline $\mathrm{PaO}_{2} / \mathrm{FiO}_{2}$ & $192(115-278)$ & $106(83-141)$ & $129(92-207)$ & $270(198-360)$ & $<0.001$ \\
\hline Plateau pressure (mmHg) & $20(17-25)$ & $24(20-28)$ & $20(17-25)$ & $20(17-25)$ & 0.006 \\
\hline Static compliance $\left(\mathrm{mL} / \mathrm{cm} \mathrm{H}_{2} \mathrm{O}\right)$ & $33(26-45)$ & $31(24-36)$ & $33(25-45)$ & $35(26-46)$ & 0.071 \\
\hline Driving pressure $\left(\mathrm{cm} \mathrm{H}_{2} \mathrm{O}\right)$ & $14(11-19)$ & $15(12-18)$ & $14(11-19)$ & $14(11-19)$ & 0.117 \\
\hline \multicolumn{6}{|l|}{ Intensive care unit, day 1} \\
\hline Tidal volume (mL/kg PBW) & $8.0(7.0-8.8)$ & $7.5(6.5-8.3)$ & $8.0(7.0-9.0)$ & $7.7(7.0-8.8)$ & 0.220 \\
\hline $\mathrm{FiO}_{2}$ & $46(40-60)$ & $46(40-57)$ & $46(40-60)$ & $46(40-60)$ & 0.616 \\
\hline PEEP & $5(5-6)$ & $6(5-8)$ & $5(5-6)$ & $5(5-6)$ & 0.002 \\
\hline $\mathrm{pH}$ & $7.35(7.29-7.40)$ & $7.38(7.30-7.41)$ & $7.35(7.29-7.39)$ & $7.35(7.29-7.40)$ & 0.377 \\
\hline $\mathrm{PaO}_{2}(\mathrm{~mm} \mathrm{Hg})$ & $97(82-113)$ & $96(83-113)$ & $94(79-109)$ & $100(84-117)$ & 0.002 \\
\hline $\mathrm{PaO}_{2} / \mathrm{FiO}_{2}$ & $207(163-258)$ & $206(169-244)$ & $200(156-257)$ & $210(170-260)$ & 0.053 \\
\hline Plateau pressure (mmHg) & $21(18-25)$ & $22(20-25)$ & $21(18-25)$ & $21(18-25)$ & 0.266 \\
\hline Static compliance $\left(\mathrm{mL} / \mathrm{cm} \mathrm{H}_{2} \mathrm{O}\right)$ & $35(27-43)$ & $33(27-37)$ & $34(27-43)$ & $35(28-43)$ & 0.181 \\
\hline Driving pressure $\left(\mathrm{cm} \mathrm{H}_{2} \mathrm{O}\right)$ & $16(13-19)$ & $15(13-18)$ & $16(13-19)$ & $16(13-19)$ & 0.342 \\
\hline
\end{tabular}

Continuous variables are reported as median (interquartile range). $P$ values are from one-way analysis of variance. Bonferroni correction: $\mathrm{a} / \mathrm{n}$ of comparisons $=$ $0.05 / 3=0.017$. $P B W$ predicted body weight, $\mathrm{FiO}_{2}$ fraction of inspired oxygen, $\mathrm{PEEP}$ positive end-expiratory pressure, $\mathrm{PaO}_{2}$ partial pressure of arterial oxygen

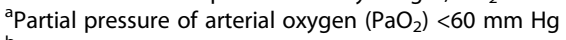

${ }^{\mathrm{b}} \mathrm{PaO}_{2} 60-120 \mathrm{~mm} \mathrm{Hg}$

${ }^{\mathrm{c}} \mathrm{PaO}_{2}>120 \mathrm{~mm} \mathrm{Hg}$

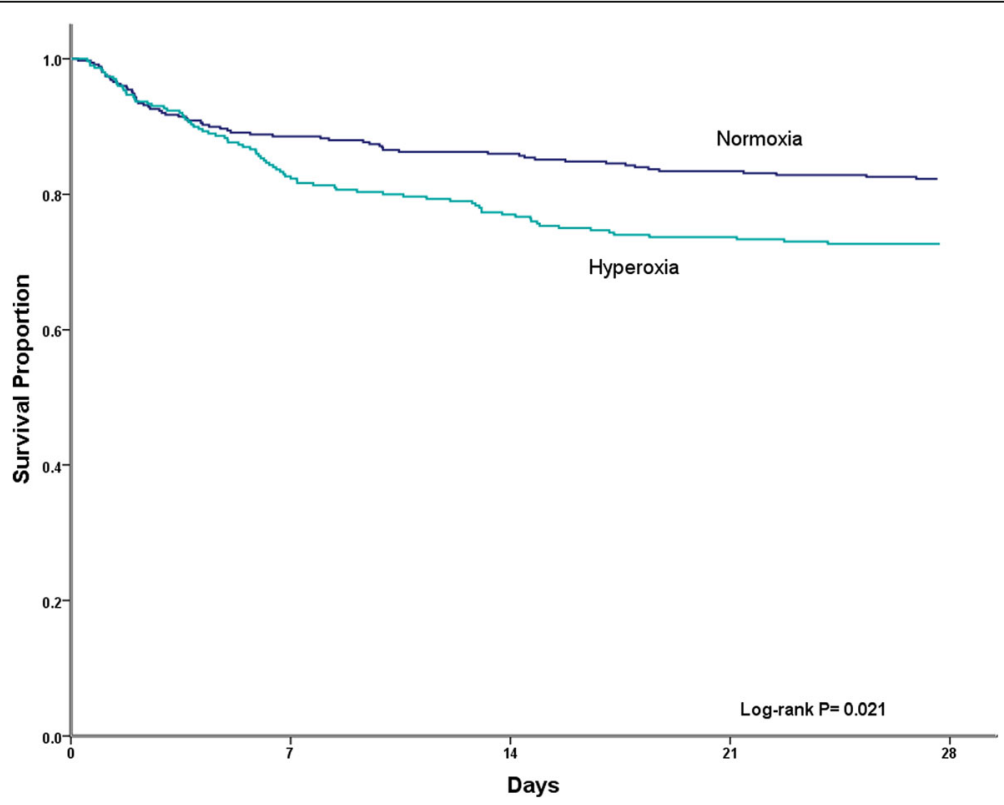

Fig. 2 Kaplan-Meier survival curve between the hyperoxia and normoxia groups 
Table 3 Primary and secondary outcomes according to initial oxygenation group

\begin{tabular}{|c|c|c|c|c|c|c|}
\hline Outcome & $\begin{array}{l}\text { All subjects } \\
\mathrm{n}=688\end{array}$ & $\begin{array}{l}\text { ED hypoxia }^{a} \\
n=38\end{array}$ & $\begin{array}{l}\text { ED normoxia } \\
\mathrm{n}=350\end{array}$ & $\begin{array}{l}\text { ED hyperoxia }^{c} \\
\mathrm{n}=300\end{array}$ & Adjusted odds ratio or between-group difference $(95 \% \mathrm{Cl})$ & $P$ value \\
\hline \multicolumn{7}{|c|}{ Primary outcome, $n(\%)$} \\
\hline Mortality & $162(23.5)$ & $5(13.2)$ & $68(19.4)$ & $89(29.7)$ & $1.95(1.34-2.85)$ & $<0.001$ \\
\hline \multicolumn{7}{|c|}{ Secondary outcomes (days) } \\
\hline Ventilator-free & $16.5(10.9)$ & $20.3(9.7)$ & $17.9(10.3)$ & $14.2(11.3)$ & $3.7(2.0-5.4)$ & $<0.001$ \\
\hline ICU-free & $15.2(10.3)$ & $17.9(9.1)$ & $16.7(9.8)$ & $13.2(10.7)$ & $3.5(1.9-5.1)$ & $<0.001$ \\
\hline Hospital-free & $10.7(9.2)$ & $12.8(9.3)$ & $11.9(9.0)$ & $8.9(9.1)$ & $2.9(1.5-4.3)$ & $<0.001$ \\
\hline
\end{tabular}

The $P$ value for the primary outcome measure was from the Wald test estimated using a logistic regression model accounting for age, gender, Acute Physiology and Chronic Health Evaluation II score, lactate, emergency department tidal volume, emergency department (ED) plateau pressure, intensive care unit partial pressure of arterial oxygen $\left(\mathrm{P}_{\mathrm{a}} \mathrm{O}_{2}\right)$, and oxygen exposure group. The $P$ values for the secondary outcomes are from the independent sample $t$ test, comparing the normoxic and hyperoxic groups

${ }^{\mathrm{a}} \mathrm{PaO}_{2}<60 \mathrm{~mm} \mathrm{Hg}$

${ }^{\mathrm{b}} \mathrm{PaO}_{2} 60-120 \mathrm{~mm} \mathrm{Hg}$

${ }^{\mathrm{C}} \mathrm{PaO}_{2}>120 \mathrm{~mm} \mathrm{Hg}$

injurious, and with prolonged exposure [6, 9]. In addition to the production of free radicals, hyperoxia can cause vasoconstriction and a paradoxical decrease in oxygen delivery (within minutes) to prone regional areas (i.e. heart, brain, kidney) [30, 31]. These facts may help explain the findings in the current study, as the hyperoxia observed in the current investigation was in the most immediate post-intubation period, and much more pronounced $\left(\mathrm{P}_{\mathrm{a}} \mathrm{O}_{2} 189 \mathrm{~mm} \mathrm{Hg}(146-249)\right.$ when compared to normoxic patients $\left(\mathrm{P}_{\mathrm{a}} \mathrm{O}_{2} 88 \mathrm{~mm} \mathrm{Hg}(76-101)\right)$. Additionally, the data suggest that our findings represent an effect of ED hyperoxia (and not carry-over into the ICU), as these patients were normoxic after ICU admission (Table 2), and throughout their ICU stay (Additional file 2: Table S1). This suggests that targeting normoxia from the initiation of mechanical ventilation may improve outcome, and makes complete physiologic sense.

\section{Significance of study findings}

A single-center randomized controlled trial (RCT) recently showed an absolute risk reduction in hospital mortality of $8.2 \%$ when normoxia was targeted in ICU patients; this is similar to the $8.3 \%$ difference in mortality between the normoxia and hyperoxia groups observed in this study, with survival curves of similar appearance [32]. However, another recent RCT failed to demonstrate any survival signal with a conservative oxygen target in mechanically ventilated patients, though this was a pilot feasibility study not powered for mortality [33]. Our study supports the notion that clinicians liberally administer oxygen in the immediate period of mechanical ventilation and routinely accept (and perhaps even target) hyperoxia. It also supports that this practice may be harmful. While no concrete recommendations can be given on the optimal $\mathrm{P}_{\mathrm{a}} \mathrm{O}_{2}$ in mechanically ventilated ED patients, our data suggest little downside in

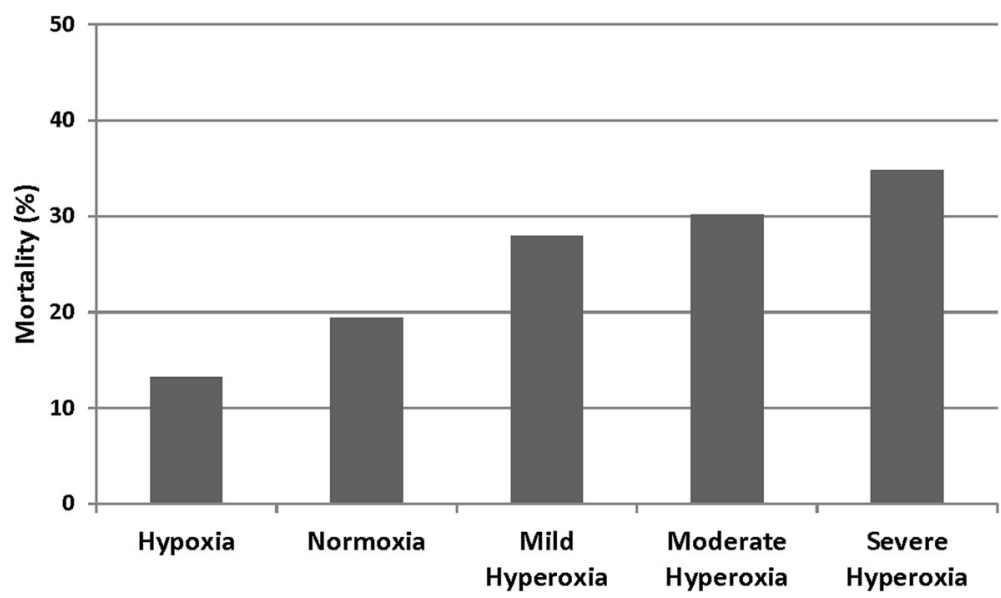

Fig. 3 Mortality across oxygenation groups, including hyperoxia subgroups. Hypoxia, partial pressure of arterial oxygen $\left(\mathrm{P}_{\mathrm{a}} \mathrm{O}_{2}\right)<60 \mathrm{~mm} \mathrm{Hg}_{\text {; }}$ normoxia, $\mathrm{P}_{\mathrm{a}} \mathrm{O}_{2}$ 60-120 mm Hg; mild hyperoxia, $\mathrm{P}_{\mathrm{a}} \mathrm{O}_{2}$ 121-200 mm Hg; moderate hyperoxia, $\mathrm{P}_{\mathrm{a}} \mathrm{O}_{2}$ 201-300 mm Hg; severe hyperoxia, $\mathrm{P}_{\mathrm{a}} \mathrm{O}_{2}>300 \mathrm{~mm} \mathrm{Hg}$ 
immediately targeting normoxia, and provide data to suggest an opportunity to study this further in the ED.

This investigation has several limitations. It was a single-center study, and the oxygen administration practices and incidence of ED hyperoxia may not be externally valid or apply to other centers. Excess $\mathrm{F}_{\mathrm{i}} \mathrm{O}_{2}$ administration in mechanically ventilated patients has been well-documented in the literature, suggesting these data are generalizable outside of our hospital [2, 29]. Given the study design, unmeasured confounders linked to hyperoxia could have accounted for the excess mortality in the hyperoxia group. For example, clinicians may err on the side of hyperoxia intentionally in conditions associated with lower oxygen delivery (i.e. anemia, low cardiac output), greater hypoperfusion, or higher illness severity. However, compared to the normoxia group, hyperoxic patients had similar hemoglobin levels, blood pressure, vasopressor use, lactate, illness severity, and fluid administration. Imbalances in baseline characteristics may have also influenced results, though these were adjusted for in our multivariable analysis. Nevertheless, the current results provide more evidence for the avoidance of excess oxygen, which is not providing any additional therapeutic benefit. While causation cannot be established with the design, the results are consistent with the majority of data on this topic. Furthermore, dose-response suggests causality, and greater mortality was observed across subgroups of increasing ED hyperoxia. The study also reflects real world practice in oxygen management, as it was conducted outside the auspice of a rigidly controlled randomized trial. There is potential for selection bias given the number of excluded patients in the study. The majority of exclusions were due to very early deaths or extubation within 24 hours; it is unlikely that acute hyperoxia would influence outcome in the acutely terminal patient or those stable enough to be extubated within 24 hours. Also, to better isolate an association between ED oxygen exposure and outcome, the analysis was restricted to those patients who were normoxic while in the ICU. Finally, the timing of arterial blood gas analyses was not obtained as part of a formal protocol therefore the exact duration of hyperoxia exposure is unknown. However, we observed marked differences between ED and day 1 ICU oxygenation data, suggesting that the primary exposure was driven by the ED. Furthermore, there were little differences between ICU day 1 data and data calculated over the entire time of mechanical ventilation, suggesting stability in oxygenation data over time (i.e. transient exposures in the ICU were less likely). However, without prospectively following all oxygenation and mechanical ventilation parameters closely in the ICU over time, there still exists the possibility that hyperoxia in the ICU affected some of our results, though our suspicion of this is low. In the future, the exact timing of all mechanical ventilator changes, oxygenation data, and arterial blood gas sampling should be documented to ensure that the exposure (and duration) has been reliably determined.

\section{Conclusions}

ED exposure to hyperoxia is common and associated with increased mortality in mechanically ventilated patients achieving normoxia after admission. This suggests that hyperoxia in the immediate post-intubation period could be particularly injurious, and targeting normoxia at the initiation of mechanical ventilation may improve outcome.

\section{Additional files}

Additional file 1: Definitions of comorbid conditions. (DOCX $13 \mathrm{~kb}$ )

Additional file 2: Table S1. Ventilator variables during the entire intensive care unit stay. (DOCX 15 kb)

Additional file 3: Table S2. Multivariable logistic regression model with in-hospital mortality as the dependent variable. (DOCX $15 \mathrm{~kb}$ )

Additional file 4: Figure S1. Kaplan-Meier survival curve between the hyperoxia subgroups and the normoxia group. (TIFF $76 \mathrm{~kb}$ )

\section{Abbreviations}

ANOVA: One-way analysis of variance; aOR: Adjusted odds ratio; APACHE: Acute Physiology and Chronic Health Evaluation; ARDS: Acute respiratory distress syndrome; $\mathrm{Cl}$ : Confidence interval; $\mathrm{C}_{\mathrm{RS}}$ : Static compliance of the respiratory system; ED: Emergency department; $\mathrm{F}_{\mathrm{i}} \mathrm{O}_{2}$ : Fraction of inspired oxygen; ICU: Intensive care unit; IQR: Interquartile range; OR: Odds ratio; $\mathrm{P}_{\mathrm{a}} \mathrm{O}_{2}$ : Partial pressure of arterial oxygen; PEEP: Positive end-expiratory pressure; RCT: Randomized controlled trial; SD: Standard deviation; $\mathrm{SpO}_{2}$ : Peripheral arterial oxygen saturation

\section{Acknowledgements}

Not applicable.

\section{Funding}

BMF was funded by the KL2 Career Development Award, and this research was supported by the Washington University Institute of Clinical and Translational Sciences (Grants UL1 TR000448 and KL2 TR000450) from the National Center for Advancing Translational Sciences (NCATS). NMM was supported by grant funds from the Health Resources and Services

Administration. EA was supported by the Washington University School of Medicine Faculty Scholars grant and the Foundation for Barnes-Jewish Hospital. MHK was supported by the Barnes-Jewish Hospital Foundation. BWR was supported by a grant from the National Institutes of Health/National Heart, Lung, and Blood Institute (K23HL126979). Funders played no role in the design and conduct of the study, nor in the collection, management, analysis, and interpretation of the data, nor in the preparation, review, or approval of the manuscript.

\section{Availability of data and materials}

The datasets used and/or analyzed during the current study are available from the corresponding author on reasonable request.

\section{Authors' contributions}

BMF had full access to all of the data in the study and takes responsibility for the integrity of the data and accuracy of the data analysis. Study concept and design: BMF, DP. Acquisition of data: BMF, DP. Analysis and interpretation of data: BMF, DP, NMM, EA, BTW, ST, MHK, BWR. Drafting of the manuscript: BMF, DP. Critical revision of the manuscript for important intellectual content: BMF, DP, NMM, EA, BTW, ST, MHK, BWR. Statistical 
analysis: BMF, DP. Obtained funding: BMF. Administrative and technical support: BMF, DP. Study supervision: BMF. All authors read and approved the final manuscript.

\section{Ethics approval and consent to participate}

This study was approved by the Human Research Protection Office of Washington University in St. Louis under waiver of informed consent.

\section{Consent for publication}

Not applicable.

\section{Competing interests}

The authors declare that they have no competing interests.

\section{Publisher's Note}

Springer Nature remains neutral with regard to jurisdictional claims in published maps and institutional affiliations.

\section{Author details}

'Department of Emergency Medicine, Washington University School of Medicine in St. Louis, St. Louis, MO 63110, USA. ${ }^{2}$ Department of Anesthesiology, Division of Critical Care Medicine, Washington University School of Medicine in St. Louis, St. Louis, MO 63110, USA. ${ }^{3}$ Department of Medicine, Division of Pulmonary and Critical Care Medicine, Washington University School of Medicine in St. Louis, St. Louis, MO 63110, USA. ${ }^{4}$ Department of Emergency Medicine, Roy J. and Lucille A. Carver College of Medicine, University of lowa, 200 Hawkins Drive, 1008 RCP, lowa City, IA 52242, USA. ${ }^{5}$ Department of Anesthesiology, Division of Critical Care Medicine, Roy J. and Lucille A. Carver College of Medicine, University of lowa, 200 Hawkins Drive, 1008 RCP, lowa City, IA 52242, USA. ${ }^{6}$ Department of Medicine, Division of Critical Care Medicine, Cooper University Hospital, One Cooper Plaza, K152, Camden, NJ 08103, USA. Department of Emergency Medicine, Cooper University Hospital, One Cooper Plaza, K152, Camden, NJ 08103, USA.

Received: 9 August 2017 Accepted: 15 December 2017

Published online: 18 January 2018

\section{References}

1. O'driscoll B, Howard L, Earis J, Mak V. BTS guideline for oxygen use in adults in healthcare and emergency settings. Thorax. 2017;72 Suppl 1:ii1-ii90.

2. de Graaff AE, Dongelmans DA, Binnekade JM, de Jonge E. Clinicians response to hyperoxia in ventilated patients in a Dutch ICU depends on the level of FiO2. Intensive Care Med. 2011:37(1):46-51.

3. Helmerhorst HJ, Schultz MJ, van der Voort PH, Bosman RJ, Juffermans NP, de Jonge $E$, van Westerloo DJ. Self-reported attitudes versus actual practice of oxygen therapy by ICU physicians and nurses. Ann Intensive Care. 2014;4(1):23.

4. Suzuki S, Eastwood GM, Peck L, Glassford NJ, Bellomo R. Current oxygen management in mechanically ventilated patients: a prospective observational cohort study. J Crit Care. 2013;28(5):647-54.

5. Damiani E, Adrario E, Girardis M, Romano R, Pelaia P, Singer M, Donati A. Arterial hyperoxia and mortality in critically ill patients: a systematic review and meta-analysis. Crit Care. 2014;18(6):711.

6. Helmerhorst HJ, Roos-Blom M-J, van Westerloo DJ, de Jonge E. Association between arterial hyperoxia and outcome in subsets of critical illness: a systematic review, meta-analysis, and meta-regression of cohort studies. Crit Care Med. 2015;43(7):1508-19.

7. Stub D, Smith K, Bernard S, Nehme Z, Stephenson M, Bray JE, Cameron P, Barger B, Ellims AH, Taylor AJ. Air versus oxygen in ST-segment elevation myocardial infarction. Circulation. 2015;131(24):2143-50.

8. de Jonge E, Peelen L, Keijzers PJ, Joore H, de Lange D, van der Voort PH, Bosman RJ, de Waal RA, Wesselink R, de Keizer NF. Association between administered oxygen, arterial partial oxygen pressure and mortality in mechanically ventilated intensive care unit patients. Crit Care. 2008;12(6):R156.

9. Helmerhorst HJ, Arts DL, Schultz MJ, van der Voort PH, Abu-Hanna A, de

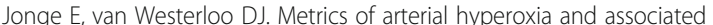
outcomes in critical care. Crit Care Med. 2017;45(2):187-95.

10. Kilgannon JH, Jones AE, Shapiro NI, Angelos MG, Milcarek B, Hunter K, Parrillo JE, Trzeciak S, Investigators EMSRN. Association between arterial hyperoxia following resuscitation from cardiac arrest and in-hospital mortality. JAMA. 2010;303(21):2165-71.
11. Rincon F, Kang J, Maltenfort M, Vibbert M, Urtecho J, Athar MK, Jallo J, Pineda CC, Tzeng D, McBride W. Association between hyperoxia and mortality after stroke: a multicenter cohort study. Crit Care Med. 2014; 42(2):387-96

12. Janz DR, Hollenbeck RD, Pollock JS, McPherson JA, Rice TW. Hyperoxia is associated with increased mortality in patients treated with mild therapeutic hypothermia after sudden cardiac arrest. Crit Care Med. 2012; 40(12):3135.

13. Kilgannon JH, Jones AE, Parrillo JE, Dellinger RP, Milcarek B, Hunter K, Shapiro NI, Trzeciak S. Relationship between supranormal oxygen tension and outcome after resuscitation from cardiac arrest. Circulation. 2011; 123(23):2717-22

14. Brenner M, Stein D, Hu P, Kufera J, Wooford M, Scalea T. Association between early hyperoxia and worse outcomes after traumatic brain injury. Arch Surg. 2012;147(11):1042-6.

15. Davis DP, Meade Jr W, Sise MJ, Kennedy F, Simon F, Tominaga G, Steele J, Coimbra R. Both hypoxemia and extreme hyperoxemia may be detrimental in patients with severe traumatic brain injury. J Neurotrauma. 2009;26(12): 2217-23.

16. Rincon F, Kang J, Vibbert M, Urtecho J, Athar MK, Jallo J. Significance of arterial hyperoxia and relationship with case fatality in traumatic brain injury: a multicentre cohort study. J Neurol Neurosurg Psychiatry. 2014;85(7): 799-805.

17. Andrade P, Dos Santos J, Silva A, Wilbert D, Cavassani S, Oliveira-Junior I. Influence of hyperoxia and mechanical ventilation in lung inflammation and diaphragm function in aged versus adult rats. Inflammation. 2014;37(2):486.

18. Cavassani SS, Junqueira VBC, Moraes JB, Luzo KK, Silva CMA, Barros M, Marinho M, Simões RS, Oliveira-Júnior IS. Short courses of mechanical ventilation with high-O2 levels in elderly rat lungs. Acta Cir Bras. 2011;26(2):107-13.

19. Li L-F, Liao S-K, Ko Y-S, Lee C-H, Quinn DA. Hyperoxia increases ventilatorinduced lung injury via mitogen-activated protein kinases: a prospective, controlled animal experiment. Crit Care. 2007:11(1):R25.

20. Helmerhorst HJ, Schouten LR, Wagenaar GT, Juffermans NP, Roelofs JJ, Schultz MJ, de Jonge E, van Westerloo DJ. Hyperoxia provokes a time-and dose-dependent inflammatory response in mechanically ventilated mice, irrespective of tidal volumes. Intensive Care Med Exp. 2017:5(1):27.

21. Fuller BM, Mohr NM, Dettmer M, Kennedy S, Cullison K, Bavolek R, Rathert N, McCammon C. Mechanical ventilation and acute lung injury in emergency department patients with severe sepsis and septic shock: an observational study. Acad Emerg Med. 2013;20(7):659-69.

22. Fuller BM, Mohr NM, Miller CN, Deitchman AR, Levine BJ, Castagno N, Hassebroek EC, Dhedhi A, Scott-Wittenborn N, Grace E. Mechanical ventilation and ARDS in the ED: a multicenter, observational, prospective, cross-sectional study. CHEST J. 2015;148(2):365-74.

23. Rose L, Gray S, Burns K, Atzema C, Kiss A, Worster A, Scales DC, Rubenfeld G, Lee J. Emergency department length of stay for patients requiring mechanical ventilation: a prospective observational stud. Scand J Trauma Resusc Emerg Med. 2012;20(1):30

24. Fuller BM, Ferguson IT, Mohr NM, Drewry AM, Palmer C, Wessman BT, Ablordeppey E, Keeperman J, Stephens RJ, Briscoe CC. Lung-protective ventilation initiated in the emergency department (LOV-ED): a quasiexperimental, before-after trial. Ann Emerg Med. 2017;70(3):406-18.

25. Fuller BM, Ferguson I, Mohr NM, Stephens RJ, Briscoe CC, Kolomiets AA, Hotchkiss RS, Kollef MH. Lung-protective ventilation initiated in the emergency department (LOV-ED): a study protocol for a quasi-experimental, before-after trial aimed at reducing pulmonary complications. BMJ Open. 2016:6(4):e010991.

26. ARDS Definition Task Force, Ranieri VM, Rubenfeld GD, Thompson BT, Ferguson ND, Caldwell E, Fan E, Camporota L, Slutsky AS. Acute respiratory distress syndrome. The ARDS definition task force. JAMA. 2012;307(23):2526-33.

27. Eastwood G, Bellomo R, Bailey M, Taori G, Pilcher D, Young P, Beasley R. Arterial oxygen tension and mortality in mechanically ventilated patients. Intensive Care Med. 2012;38(1):91-8.

28. Stolmeijer R, ter Maaten JC, Zijlstra JG, Ligtenberg JJ. Oxygen therapy for sepsis patients in the emergency department: a little less? Eur J Emerg Med. 2014;21(3):233-5.

29. Panwar R, Capellier G, Schmutz N, Davies A, Cooper D, Bailey M, Baguley D, Pilcher D, Bellomo R. Current oxygenation practice in ventilated patients-an observational cohort study. Anaesth Intensive Care. 2013;41(4):505

30. Cornet AD, Kooter AJ, Peters MJ, Smulders YM. The potential harm of oxygen therapy in medical emergencies. Crit Care. 2013;17(2):313. 
31. Iscoe S, Fisher JA. Hyperoxia-induced hypocapnia*: an underappreciated risk. Chest. 2005;128(1):430

32. Girardis M, Busani S, Damiani E, Donati A, Rinaldi L, Marudi A, Morelli A, Antonelli M, Singer M. Effect of conservative vs conventional oxygen therapy on mortality among patients in an intensive care unit: the oxygenICU randomized clinical trial. JAMA. 2016;316(15):1583-9.

33. Panwar R, Hardie M, Bellomo R, Barrot L, Eastwood GM, Young PJ, Capellier G, Harrigan PW, Bailey M. Conservative versus liberal oxygenation targets for mechanically ventilated patients. A pilot multicenter randomized controlled trial. Am J Respir Crit Care Med. 2016;193(1):43-51.

Submit your next manuscript to BioMed Central and we will help you at every step:

- We accept pre-submission inquiries

- Our selector tool helps you to find the most relevant journal

- We provide round the clock customer support

- Convenient online submission

- Thorough peer review

- Inclusion in PubMed and all major indexing services

- Maximum visibility for your research

Submit your manuscript at www.biomedcentral.com/submit 